\title{
A NOVA HISTÓRIA, SUA MORAL, SUA ÉTICA E SUA ARTE
}

\author{
Wilson Alves de Paiva*
}

\section{0 deslumbramento}

“Não concordo com Fukuyama, com essa história de fim da história. Não tem fim da história nenhum. Mas há uma nova história. É cedo, talvez, para vê-la com nitidez. Mas há, ou vai haver breve, uma nova história”.

Fernando Henrique Cardoso

Assim se manifesta o presidente brasileiro ao responder seu interlocutor que o questiona sobre a crise do Estado Nacional, ou seja, do modelo de Estado que estamos acostumados e que se tem perpetuado por décadas e gerações.

Inequivocamente, vivemos hoje tempos diferentes. Uma era diferente, anômala, disforme, cujas nuanças se encontram em formação constante num movimento que confundiria até Marx ou Hegel. Como afirma o presidente-sociólogo, não podemos ainda distinguir tais nuanças com nitidez, "Mas há, ou vai haver breve, uma nova história". Isso porque os acontecimentos atuais levam muitos a afirmar que verdadeiramente deixamos a modernidade com seu racionalismo, existencialismo, materialismo e vislumbramos, agora, sob a égide do pós-industrialismo, do pós-capitalismo, não uma crise de matrizes ou parâmetros, mas uma abstração completa da realidade. Os "ismos" atuais passam a buscar um consenso entre os extremos experimentados pela história. O contemporâneo não é tão materialista como pregavam Marx e Nietzsche, mas não tão espiritual como queria Santo Agostinho, não tão infinito na concepção de Parmênides, mas não tão finito no viés existencialista. Não é tão dialético como queriam Sócrates e Aristóteles, mas não tão alienado às leis naturais da sociedade como evocou Durkheim. O contemporâneo é... Bem, o contemporâneo é abstração e ponto final.

* Licenciado Pleno em Pedagogia e Especialização em Psicopedagogia. Assessor Técnico da Secretaria de Executiva de Educação do Estado do Pará (Em licença para Pós-Graduação). Professor de Estrutura e Educação Brasileira da Faculdade de Educação da Universidade Federal de Goiás. Consultor em Educação. Ex-Secretário Municipal de Educação de Trairão (PA).

Rua: 12-A, n. ${ }^{\circ}$ 40, Setor Oeste, Trindade- GO, CEP 75380-000.

Telefone: (62) 5054434

E-mail: paivaw@bol.com.br e wp@riotapajos.com.br

Site pessoal: www.wilsonpaiva.kit.net 
Mas o problema é que no meio dessa abstração, torna-se complicado definir com exatidão o papel do homem na sociedade, fica difícil diferenciar a autêntica criação da pura pastichização. Sem parâmetros, sem matrizes, sem valores que traduzem aspirações universais e necessidades imediatas dos povos, a humanidade se perde em sua própria abstração, quando não é subjugada pelo poder de alguma força hegemônica, uma maneira própria de ver essa abstração.

Seguindo a corrente das forças dominantes (leia-se ideologia), podemos dizer que Fukuyama está certo. "Liberal democracy may constitute the end point of mankind's ideological evolution".

Tanto Marx como Hegel acreditavam que a evolução histórica teria um fim quando a humanidade atingisse uma forma de sociedade que viesse a satisfazer as necessidades sociais. Ora, para os liberais, ou neoliberais, já atingimos a plena democracia, o pleno respeito ao cidadão e a todas as instituições democráticas, e a sociedade pós-industrial dará conta de resolver as questões mínimas e as resistências a essa nova visão e linguagem. Analisando o que diz Jameson, Gramsci, Bourdieu e, mais recentemente, Pablo Gentili e Michael Apple, tendemos a analisar que o engodo da democratização acelerada, da globalização, da internacionalização de valores morais, espirituais e materiais mascara a hegemonia do capital sobre a humanização da sociedade.

A crise do Estado é a crise da sociedade. Ofuscam-se os Estados, diminuindo-lhes o valor, ofuscam-se as relações sociais, as relações humanas, os valores, as artes e tudo que tínhamos emanados do belo plotiniano. Configura-se uma nova história, na qual, nas palavras do presidente, é cedo para vêla com nitidez. É, portanto, o deslumbramento diante de uma história que muda costumes, regras, arte, conceitos e desmistifica o belo em favor da pósmodernidade.

Difícil não é contemplar, discutir ou mesmo digladiar com todos esses aspectos. Difícil é trabalhá-los coerentemente no espaço escolar. Como fica o professor diante de tudo isso? Como se dá seu deslumbramento? Sua inserção? Como ele formata e repassa tudo isso aos seus "pupilos"? Ele reproduz ou transforma? Adapta ou copia?

Como a escola não é um ambiente isolado, mas um organismo vivo, orgânico, latente, passa a tomar corpo nessa nova história, passa a ganhar força e significação. É por ela que passam todos os seres humanos, é ela que forma e pode ser ela que transforma. O papel do professor passa a ser de uma importância nunca antes experimentada, porque, mais do que nunca, a educação é a chave da pós-modernidade. E isso implica em alguns aspectos a serem analisados: o aspecto existencial da própria pós-modernidade e as imbricações socioculturais advindas desse processo. É o que veremos mais adiante. 


\section{Pós-modernidade?}

Dado que uma sociedade, segundo Smith, não é feliz quando a maioria sofre... é necessário concluir que a infelicidade da sociedade é a meta da economia política. As únicas engrenagens acionadas pela economia política são a avidez pelo dinheiro e a guerra entre aqueles que padecem disso, a concorrência.

Karl Marx

Seguindo a lógica de Marx, a avidez pelo dinheiro, ou seja, o lucro, tem impulsionado o projeto social, que orientado pela teoria do capital humano", trouxe para o contexto histórico da atualidade a relação entre educação e desenvolvimento econômico. As perspectivas neoliberais mantêm a ênfase de que a educação serve para melhorar o desempenho do mercado e para a expansão da produtividade. De forma que as engrenagens impõem a "qualidade total" como norteadora das ações educacionais. A Declaração Mundial de Educação para Todos é um documento baseado nos princípios de igualdade, mas também no da competitividade do mercado. Com isso, a exigência sobre o professor se faz ao nível da sua eficiência em dominar conteúdos e códigos que veiculam a tecnologia produzida nos grandes centros.

Mudança de tamanha envergadura significa mudança no papel do professor o qual deverá dominar o produto dessa nova concepção social, processá-lo por capacidade de reflexão crítica e trabalhá-lo de forma criativa em sua prática pedagógica.

Nessa reflexão, pode-se questionar: A nova história seria uma nova era, uma ruptura com a modernidade? Os traços que delineiam a atualidade são configurações de uma pós-modernidade? Ou seria apenas um desejo de ruptura, um estado de espírito, como afirma Rouanet? Vejamos o que diz o pensador brasileiro:

O pós-moderno é muito mais a fadiga crepuscular de uma época que parece extinguir-se ingloriamente que o hino de júbilo de manhãs que despontam.(...) Fantasiado uma pós-modernidade fictícia, o homem está querendo despedir-se de uma modemidade doente... (ROUANET, 1998, p. 269).

A modernidade, além de ser doentia, gera, ainda, um estado de esquizofrenia, termo marcadamente usado por Jameson, o qual é um dos aspectos patológicas mais arraigados e disseminados na sociedade de hoje. A economia política a produz, como afirma Marx, e gera esse estado de ansiedade que permeiam todas as ações humanas. Que o digam Freud com seus estudos do inconsciente e Piaget na explicação da formação da mente. A escola se defronta com crianças e adolescentes esquizofrênicos, porque: 
Em geral, o adolescente pretende inserir-se na sociedade dos adultos por meio de projetos, de programas de vida, de sistemas muitas vezes teóricos, de planos de reformas políticas e sociais. (PIAGETt, 1994, p. 63)

A própria escola se encontra nessa esquizofrenia pelo fato de não conhecer seu real papel no jogo de interesses político-sociais. Sobre ela recaem pressões pela qualidade total, desenvolvimento de competências, competitividade, autonomia, etc. A educação, de um ato de conflitos e do "estado de espírito" rouanetiano, que aspira uma nova era, uma nova história. Dessa forma, escrevêla é rejeitar a barbánie e a completa desconstrução do ser e do aniquilamento da raça como produto da modernidade. É promover, na visão de Boaventura, a realização dos projetos inacabados da modernidade, como a redução do fosso que separa ricos de pobres. E repetir em coro com os frankfurtianos: "É preciso evitar que Awschwetiz se repita". Se o que estamos vivendo é modernidade, período de transição ou pós-modernidade, não importa. O que importa é a promoção do ser humano em sua totalidade. É a promoção do ato educativo como um ato formador, construtivo e transformador, mas numa ótica humanizadora, na qual a tecnologia e todo e qualquer progresso econômico signifique o progresso social e o progresso do indivíduo em sua omnilateralidade.

Isso só será possível com a domínio e a compreensão do ser como imanência da Ação Divina, como imanência do belo e da utilização da ética, como canal de comunicação entre as diversas forças que definem a multifacetada sociedade brasileira ou mundial, porque.. "O mundo não é. O mundo está sendo." (PAULO FREIRE, 1996, p. 84).

Se o mundo não é, a história não é, o ser não é. Tudo está sendo. Tudo está em construção. Se ética e moral fazem parte dessa "obra de arte" que é a construção do ser, e, conseqüentemente, do mundo, ambas emanam de uma concepção geral de beleza universal, como nos diz Benedito Nunes:

A nova ciência concebeu a arte como aquele produto da atividade humana que, obedecendo a determinados princípios, tem por fim produzir artificialmente os múltiplos aspectos de uma só beleza universal, apanágio das coisas naturais. (NUNES, 2000, p. 10, o gripo é meu)

\section{0 caso da ética, da moral e do ethos actualis}

"Todos parecem ser especialistas em ética, mas talvez raros sejam os que fazem ética".

Raimunda Lucena Melo Soares

$\mathrm{O}$ advento da crise de referenciais em que vive a sociedade atual determina o fim de uma história (e não o fim da História). O fim de um 
momento histórico baseado unicamente nos pilares do racionalismo, do positivismo e da exatidão das ciências. $\mathrm{O}$ extremo contrário à medievalidade prevaleceu até tornar-se incapaz de dar respostas às angustias do fin de siècle. Não se tem ainda, mesmo no século XXI, uma definição clara do que é moral, do que é ética, do que é realmente correto.

Soares sintetiza de forma prática essa questão polêmica. Raros são os que sabem o que isso significa. Por que é tão difícil ser ético? Por que é tão difícil agir sobre o determinismo da natureza, tomando o sentido kantiano de natureza, como o reino da causalidade natural, do determinismo e controlar os impulsos? Dando seqüência à reflexão kantiana, os princípios racionais do dever, da organização, da ordem, da responsabilidade deveriam sobrepor a uma espécie de determinismo natural que se institucionalizou e se legitimou por meio das práticas sociais de autoritarismo e supremacia.

Muito se fala de ética e todos parecem ser especialistas em ética. E, apesar de tudo, tal discussão é salutar na medida que nos remete ao plano da construção, à idéia de mundo que está sendo. É salutar levar tal discussão ao campo educacional, porque é impossível dicotomizar o ensino de conteúdos e a formação ética dos educandos. A ética deve permear a prática docente tendo em vista a exigência atual de formar a autonomia, mas também a premência de formar a responsabilidade. Assim, como não há liberdade sem autoridade, não pode haver autonomia sem responsabilidade. E nisso consiste todo o ethos actualis, o ethos da moralidade: fazer o que é necessário, o que é de minha responsabilidade. Nisto o papel do professor se amplia: Não posso ensinar o que não sei. "O melhor discurso sobre ele é o exercício de sua prática” (FREIRE, 2000, p. 107). O professor deve conhecer, falar e praticar a ética, deve desenvolver o conceito de respeito mútuo, respeito ao ser como um todo, às idéias diferentes, respeito às instituições, sem, portanto, cair num quietismo fatalista e perverso. Se há a ética, há a possibilidade de transgressão da ética, dentro de uma concepção puramente ética: irromper o determinismo em favor dos princípios racionais do dever, da responsabilidade e da liberdade, frente a uma possível imposição de valores, a forças reacionárias que, de forma latente, subsiste na prática educacional.

Para tanto, a escola deve situar-se de forma construtiva nesse processo de transformação social, procurando compreender seu papel histórico e seu valor nas definições dos rumos daquilo que Rouanet chama de neomodernidade. A escola deve encampar uma prática político-pedagógica cidadã no seu dia-a-dia, mediante um intenso trabalho de participação, cooperação e respeito mútuo.

Entretanto, o que vemos, ao analisar nossas escolas, é uma prática insistentemente positivista a influenciar leis, códigos, regimentos, e, o que é pior, toda a prática pedagógica do professor. $\mathrm{O}$ autoritarismo, o diretivismo e 
o unilateralismo estão tão presentes que impedem o professor de vislumbrar as possibilidades que se levantam nesse início de milênio. Vivemos uma época extremamente capitalista, na qual os valores éticos, estéticos e morais são guiados pela ganância do lucro e da massificação da cultura de mídia, do consumo? Sim, vivemos. É um fato. Mas "A sala de aula, ao seguir outra lógica que não a do consumo, pode virar um espaço indispensável para que a criança se estruture com outros valores." (BUCCI, 2001, Revista Nova Escola).

Romanticamente falando ou "paulofreirianamente" falando, a sala de aula deve ser um ateliê onde esses "outros valores", de que fala Bucci, devam ser criados, experimentados, moldados e remodelados numa ótica de valorização do homem e da sociedade como espaço da interação e da integração. Se isso é um sonho,

Prefiro ser criticado como idealista e sonhador inveterado por continuar, sem relutar, a apostar no ser humano, a me bater por uma legislação que 0 defenda contra as arrancadas agressivas e injustas de quem transgride a própria ética. (FREIRE, 1996, p. 146)

\section{Balanço e perspectiva}

“O problematismo da arte contemporânea é, portanto, radical. Em cada obra de arte que se produz está em jogo o destino da arte; em cada uma delas o artista arrisca-se a matá-la ou a fazêla existir."

Benedito Nunes

A contemporaneidade é o resultado de um intenso diálogo do homem consigo mesmo e do homem com o mundo, cuja gênese está nas pinturas rupestres do período paleolítico. Sua expressão inicial gerou a expressão do ser. Está implícito nesse ato imanente o processo de construção do conhecimento. E construção de conhecimento é basicamente o princípio da educação. O homem da caverna estava praticando educação não só quando pintava como quando era observado e imitado pelo filho ou por outros membros do grupo. Se arte é, portanto, práxis criadora, a educação deve considerar-se arte para contemplar-se, também criadora, numa perspectiva de construção de matrizes que referenciem o momentum disforme e incerto que estamos vivendo. Está na educação, ou seja, na sua capacidade criadora, o delineamento ético, moral e estético que deverá configurar uma possível sociedade pósmoderna. 
Para Domenico de Masi, professor de filosofia da Universidade La Sapienza de Roma e autor do livro O ócio criativo, foi a sociedade moderna, industrial que expulsou o belo, o sensível, o estético do mundo do trabalho. Nunes vai mais além quando diz que o poder da técnica moderna, o trabalho industrial monótono "torna-se um processo cada vez mais impessoal, refratário às necessidades criadoras e expressivas dos indivíduos" (NUNES, 2000, p. 109).

E aqui voltamos à abstração da arte e da realidade. Seria uma fuga num puro estilo freudiano? Ou uma reação à simples imitação e/ou à força da cultura de massa? Ortega y Gasset acredita numa desumanização da arte e 0 que poderíamos estender como uma desumanização da sociedade.

Se a modernidade não resolveu seus problemas mais críticos e disso tenha decorrido essa desumanização, essa extrema degradação de valores culminando na crise ética que vivenciamos, a dita sociedade "pós-moderna" depende inteiramente de como estamos trabalhando nossa educação, até porque, para Hegel, o Ideal é determinado historicamente. O momento histórico atual deve determinar o Ideal, como fruto do processo educacional, definindo a nova história, sua moral, sua ética e sua arte.

E, parafraseando Nunes, o problematismo da educação contemporânea é, portanto, radical. Em cada tipo de educação trabalhada está em jogo seu próprio destino. Em cada tipo de educação, o professor se arrisca a matála ou fazê-la existir.

\section{Notas}

A democracia liberal pode constituir o ponto final na evolução ideológica da humanidade (tradução do autor).

Na década de 60, Theodoro Schultz defendeu a educação como fonte de investimento, trabalhando a idéia da relação educação e trabalho a partir da teoria do "capital humano".

\section{Referências}

NUNES, Benedito. Introdução à Filosofia da Arte. 5. ed. São Paulo: Ática: 2000.

PENEDOS, Álvaro J. Introdução aos Pré-Socráticos. Porto, Portugal: RésEditora, 1984. 
FREIRE, Paulo. Pedagogia da Autonomia. saberes necessários à prática educativa. 17. ed. São Paulo: Paz e Terra, 2001.

FUKUYAMA, Francis. The end of History and the Last Man. New York: Avon Books, 1998.

PIAGET, Jean. Seis estudos de Psicologia. 20. ed. Rio de Janeiro: Forense Universitária, 1994.

SOARES, Raimunda Lucena Melo(org.). Seminários de Educação: elementos para uma análise da prática educacional. Belém: Suyá, 2000.

MASI, Domenico. O ócio criativo. 2. ed. Rio de Janeiro: Sextante, 2000.

TOLEDO, Roberto Pompeu de. O Presidente segundo o Sociólogo. entrevista de Fernando Henrique Cardoso a Roberto Pompeu de Toledo. São Paulo: Companhia das Letras, 1998.

ROUANET, Sérgio Paulo. As Razões do Iluminismo. São Paulo: Companhia das letras, 1987. 